\title{
A simple method to help determine landslide susceptibility from spaceborne InSAR data: the Montescaglioso case study
}

\author{
Tommaso Carlà $^{1,2} \cdot$ Federico Raspini $^{2} \cdot$ Emanuele Intrieri $^{2}$ (1) Nicola Casagli $^{2}$
}

Received: 14 March 2016/Accepted: 30 November 2016/Published online: 10 December 2016

(c) The Author(s) 2016. This article is published with open access at Springerlink.com

\begin{abstract}
On December 3, 2013, a large complex landslide was triggered SW of the town of Montescaglioso (Southern Italy), causing the destruction of roads, commercial buildings and private dwellings, as well as several direct and indirect economic losses. A set of interferometric ground measurements acquired by the Cosmo-SkyMed satellite constellation and processed by means of the SqueeSAR algorithm was used to study the pre-event slope displacements in the entire Montescaglioso municipal area. Data span from January 30, 2012, to December 2, 2013, and show average line-of-sight velocities of $1-10 \mathrm{~mm} /$ year in the slope sector ultimately affected by the collapse. In retrospect, a time series analysis of the radar targets was performed in order to identify and characterize all the slope instabilities in proximity of the town. This was based on the setup of characteristic thresholds of displacement. The procedure permitted to locate several areas which recurrently exceeded these previously established thresholds, in consistency with the amount of precipitation. In particular, the major source of potential hazard in the area was indeed found where the December 3, 2013, landslide eventually occurred. The results of this quick data processing technique were validated through comparison with two independently developed landslide maps. This simple method, which is not supposed to diminish the importance of geomorphologic field surveys, could improve both the accuracy and the update rate of landslide susceptibility maps.
\end{abstract}

Emanuele Intrieri

Emanuele.intrieri@gmail.com

1 Regional Doctoral School of Earth Sciences, University of Firenze, Via La Pira 4, 50121 Florence, Italy

2 Department of Earth Sciences, University of Firenze, Via La Pira 4, 50121 Florence, Italy
Not relying on arbitrary or empirically derived approaches, it has the advantage of computing statistically based thresholds specific for each time series. By indicating the slope sectors in higher need of deeper in situ investigation, more support could be provided to administrative bodies for the processes of risk assessment and management.

Keywords Landslide hazard - Landslide susceptibility . Risk assessment · Satellite interferometry $\cdot$ SqueeSAR . Cosmo-SkyMed

\section{Introduction}

On December 3, 2013, after two days of intense rainfalls, a large landslide was triggered on the SW slope of the town of Montescaglioso (Matera, Southern Italy), which caused serious damage to both the road network and private dwellings and also induced the structural failure of a supermarket (Fig. 1). The official national landslide cartography PAI (Piano Assetto Idrogeologico, Plan of Hydrogeologic Setting), based on field surveys and aerial photographs, did not highlight the presence of an active slope instability in this sector. Although field surveys surely constitute the primary tool of landslide investigation and characterization, some downsides can occur when relying solely on them. In particular, full and detailed coverage of the territory may not be achieved in remote or scarcely urbanized areas and the update rate of landslide maps may not be always appropriate because of funding and/or logistic restrictions. Moreover, the reliability of in situ investigations may depend on the knowledge and experience of the surveyor.

In order to obtain the pre-event displacements of the slope sector affected by the landslide and also to better 

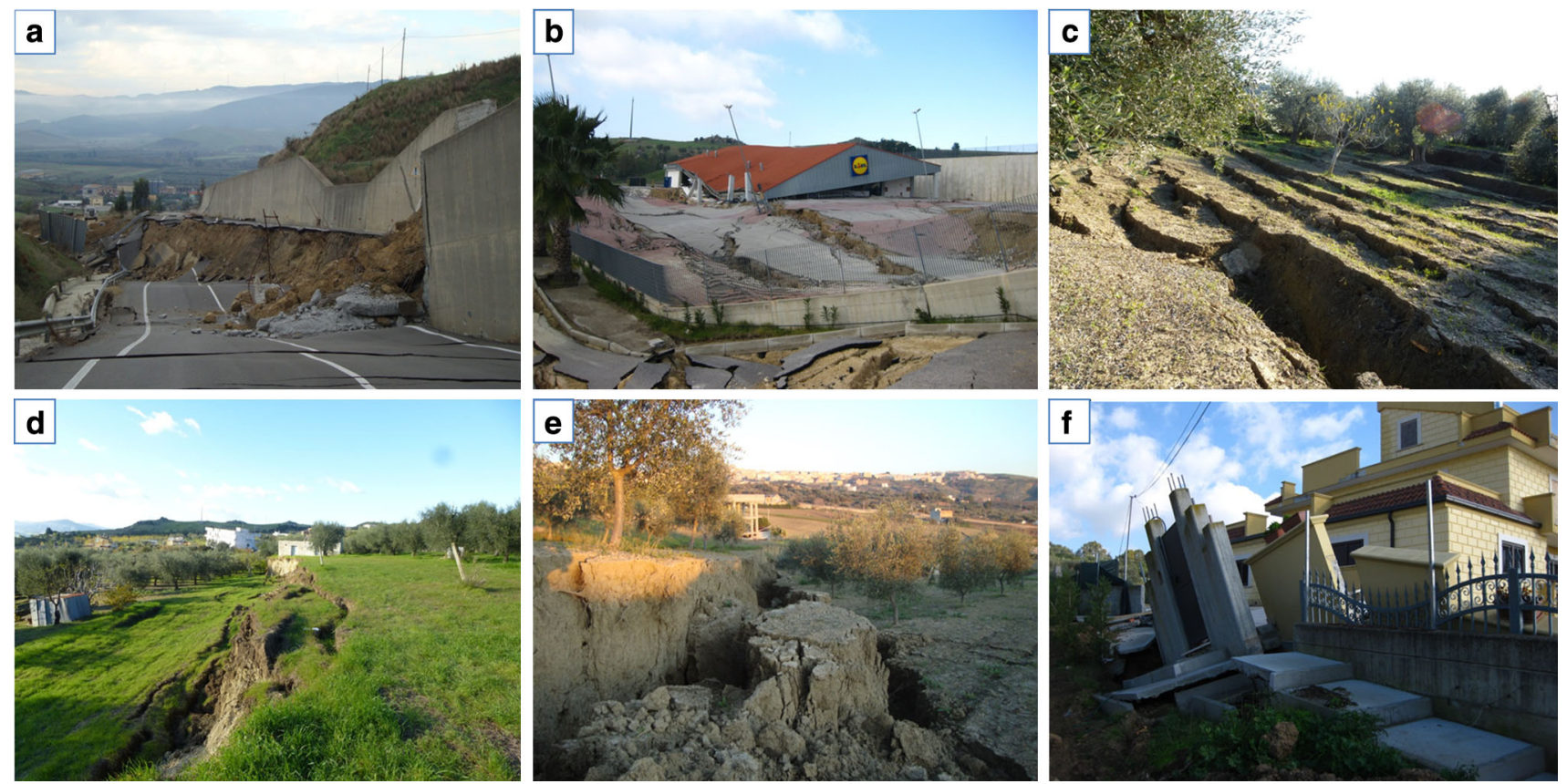

Fig. 1 Damages caused by the landslide occurred SW of the town of Montescaglioso (Matera, Southern Italy) on December 3, 2013; a, b, f disruption of streets and buildings; $\mathbf{c}$ tension cracks; d, e main scarp

locate and delimit all the slope instabilities in the Montescaglioso municipal area, a set of interferometric images acquired by the Cosmo-SkyMed satellite constellation was collected and processed by means of the SqueeSAR algorithm (Ferretti et al. 2011). Indeed, the use of spaceborne radar measures has proven over time to be a reliable source to improve landslide and subsidence identification and characterization (Metternicht et al. 2005; Strozzi et al. 2005; Farina et al. 2007; Righini et al. 2008; Cigna et al. 2011; Raspini et al. 2013; Tofani et al. 2013). The possibility to monitor the ground deformation even in remote areas, the short revisiting time of the Cosmo satellite constellation (16 days in standard orbit cycle mode; ASI 2007 and Covello et al. 2010) and the release of the new SqueeSAR algorithm, which guarantees a remarkable increase in detectable measuring points, are key features in helping to overcome some of the aforementioned issues.

In recent years, few attempts have been made to integrate landslide susceptibility maps and InSAR-derived measurements. Few works deal with the direct use of PS for quantitative landslide hazard and risk assessment. Lu et al. (2014) introduced an approach for updating landslide hazard and risk maps based on Persistent Scatterer Interferometry (PSI). Piacentini et al. (2015) exploited the results of PSI analysis for the implementation of a statistical model for landslide susceptibility; on the same subject, Oliveira et al. (2015) proposed a methodology to determine landslide susceptibility at regional scale in weak rock-dominated areas from Persistent Scatterer deformation maps. More recently, Ciampalini et al. (2016) used PSInSAR data to refine landslide susceptibility maps and to reduce false negatives. In order to provide further contribution to the topic, this paper proposes a simple procedure for the assessment of landslide susceptibility by combining the InSAR time series of deformation, ancillary data and rainfall records (identified as the triggering factor). The aim is to propose a quick and simple approach for the analysis of satellite InSAR time series, in order to produce more reliable and easily updatable landslide susceptibility maps. This shall not be seen as a replacement of field surveys as the primary mean for landslide investigation, but rather as a tool to further help municipalities and the other competent bodies for risk management to improve their decisional ability on land use, planning and protection. The proposed methodology does not rely on arbitrary or empirically derived approaches and allows for the definition of statistically based thresholds specific for each time series.

\section{Case study}

The study area is located SW of the city of Montescaglioso (Matera Province, Basilicata Region, Southern Italy). From a geological point of view it falls within the Bradanic trough, which represents the foredeep where the Apulian foreland is subsiding under the Southern Apennines. The trough has been filled by a regression sequence (coarsening 
upward) of lower-middle Pleistocene sediments, from clay on the bottom (Subapennine Clay Formation) to sand (Mount Marano Sand formation) and conglomerates (Mount Castiglione Calcarenite Formation) on top (Lazzari and Pieri 2002; D'Ecclesiis and Lorenzo 2006; Lazzari 2008). Intercalations of olistostromes witness the uplift of the Apennines chain. Along the slopes, the deposits are characterized by chaotic big-sized blocks that could be due to ancient gravity movements (Lazzari and Pieri 2002). Four stratigraphic test wells were performed in 2006 longitudinally to the SW slope of Montescaglioso and to the actual landslide body; although unfortunately the exact location of these surveys is not reported, the stratigraphy is in agreement with the mentioned literature and a geological cross section can be inferred (Fig. 2). The hilltop village of Montescaglioso rises on top of a NNW-SSE oriented, $400 \mathrm{~m}$ a.s.l. high relief. The slopes surrounding the town are marked by several crowns and lobes, highlighting a history of past landslides and indicating that the whole area is prone to gravitational instability. On this topic, Fig. 2 shows a conglomerate lens which presumably slid from the uppermost part of the hill and subsequently was partially overlain by further gravity movements. Strong erosive processes favored by the scarce vegetation and by torrential or seasonal streams are responsible for the presence of gullies along and at the base of the slopes. The hydrographic network is affected by tectonic lineations.
On December 3, 2013, a 1200-m-long, 880-m-wide landslide occurred on the SW slope of Montescaglioso. According to the classification of (Cruden and Varnes 1996), it can be classified as a rapid complex earth slide, due to its peak velocity of $0.75 \mathrm{~m} / \mathrm{min}$. During the previous 3 days, the rain gauges of Ginosa and Matera (respectively, $8 \mathrm{~km} \mathrm{SE}$ and $13 \mathrm{NW}$ of Montescaglioso) recorded $152 \mathrm{~mm}$ and $157 \mathrm{~mm}$ of rainfall (Raspini et al. 2015), adding up to the rainfall occurred during the previous two months (137.2 $\mathrm{mm}$ cumulated from October 1 to November 30, 2013). The landslide affected $500 \mathrm{~m}$ of the "Piani-Bradano" road connecting the village to the National Route 175, and disrupted $600 \mathrm{~m}$ of the Province Route Montescaglioso-Piani Bradano, thus isolating the town from the locally most important road network and causing severe direct and indirect economic losses. The phenomenon also caused the destruction of a supermarket and of some residential and commercial buildings (Fig. 1), but no casualties.

\section{Materials and methods}

\section{Dataset}

A set of 30 interferometric images were acquired in ascending geometry over the Montescaglioso municipal

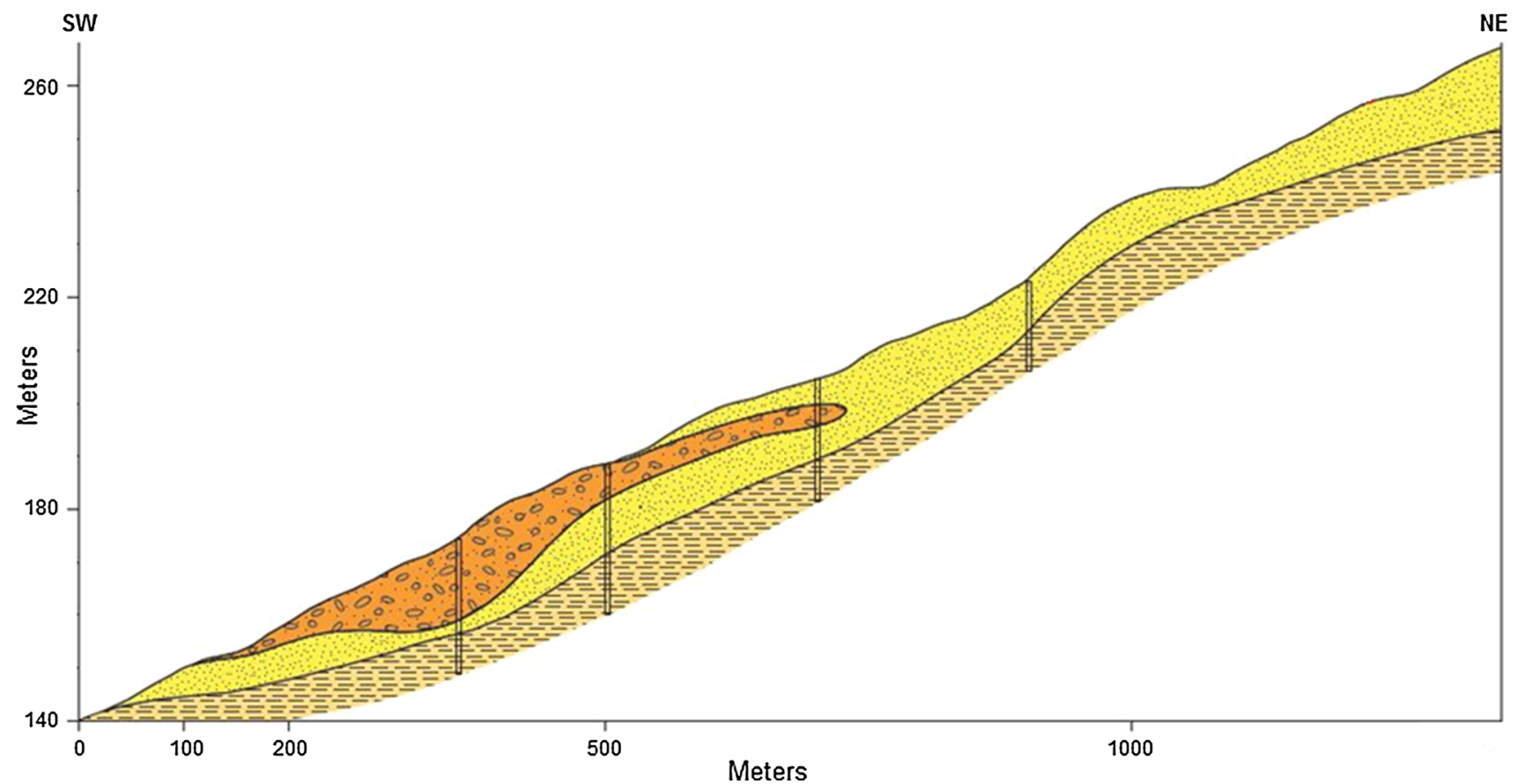

Fig. 2 Longitudinal cross section of the SW slope of Montescaglioso, showing the typical coarsening-upward trend of a stratigraphic regressive sequence. The orange formation indicates polygenic conglomerates with carbonate matrix, locally interbedded with cemented or loose yellowish sand; the yellow formation indicates yellow and reddish sands and sandy clays, locally cemented, with irregular levels of coarse sand and fine gravel; the brown formation indicates blue-gray clays, with sand 
area by the Cosmo-SkyMed (CSK) constellation between January 30, 2012, and December 2, 2013 (Fig. 3), in Stripmap mode (ground resolution of $3 \times 3 \mathrm{~m}^{2}$ and swath extension of $40 \times 40 \mathrm{~km}^{2}$ ) and with a right-looking angle between $27^{\circ}$ and $31^{\circ}$. Images were acquired in descending geometry too but have been discarded because of their poor amount (only 12 acquisitions over the same time span). The last image taken in ascending geometry happened to be made just one day prior to the landslide event. The first part of the monitoring period is characterized by a scarce amount of images; however, since October 2012, these were acquired at higher frequency and mostly at constant time interval ( 16 days and, in a few instances, 32 days; Fig. 4). Image processing was performed by Tele-Rilevamento Europa by means of the SqueeSAR algorithm. A total of 18,142 persistent and distributed scatterers were selected on the area, with each point being characterized by its own displacement time series. SqueeSAR (Ferretti et al. 2011) is a second generation PSInSAR algorithm, a method based on the processing of temporal series of co-registered SAR images acquired over the same target area. The main idea behind PSInSAR is to identify point-like targets (corresponding to single or group of few pixels) exhibiting good phase coherence over the entire observation period,

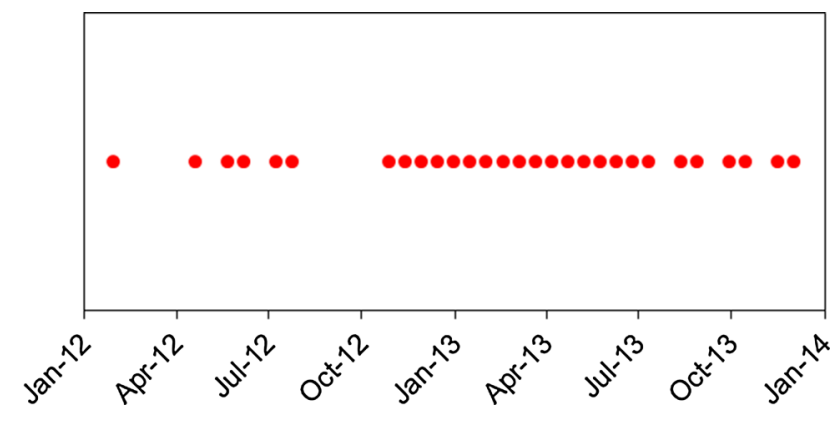

Fig. 4 Details of the available CSK dataset, spanning from 30 January 2012 to 2 December 2013

via proper statistical analyses. These coherent points are usually referred to as Permanent Scatterers (PS) and usually correspond to rock outcrops, roads, buildings and manmade objects widely available over a city, but less present in non-urban areas. Unlike the PSInSAR approach, the SqueeSAR technique allows the measurement of surface displacements by exploiting both point-wise coherent scatterers (i.e., the PS) and partially coherent Distributed Scatterers (DS). DS correspond to groups of pixels and typically are identified with homogeneous, low reflectivity areas, such as scattered outcrops, bare soil, debris-covered
Fig. 3 Velocities in $\mathrm{mm} / \mathrm{year}$ measured after the processing of the CSK interferometric images by means of the SqueeSAR algorithm on the municipal area of Montescaglioso, Southern Italy. Negative and positive values indicate movements toward and away from the sensor, respectively. The reference point for the SAR measurements sits on the stable higher portion of the hill, where also the city center is located. The boundaries of the landslide were defined through a topographic differential GPS in RTK (Real Time Kinematics) mode, which allows the survey of the position (LAT, LONG) and height of the points that can be physically accessed with the device. The accuracy of the surveys were of $\pm 2 \mathrm{~cm}$

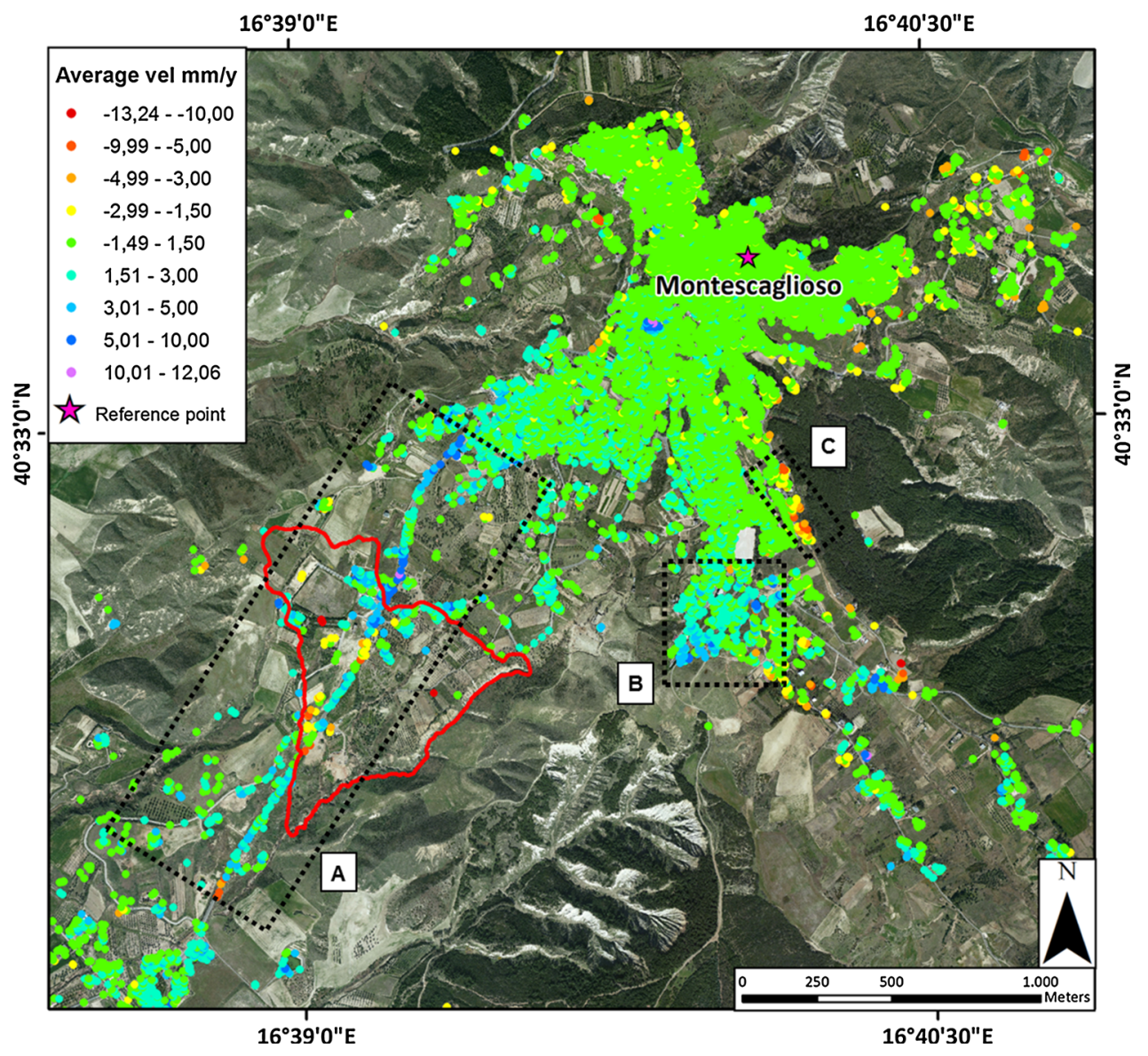


zones and non-cultivated lands. The basic idea of SqueeSAR is given a multitemporal stack of SAR scenes properly re-sampled on the same grid, to identify sets of pixels sharing the same kind of radar return, i.e., statistically homogeneous pixels. Using the amplitude (rather than complex values) of the stack of SAR images, the cumulative distribution functions of the amplitudes for the pixels (points) under consideration are obtained. The Kolmogorov-Smirnov (KS) test used in the SqueeSAR approach (Ferretti et al. 2011) is in fact a statistical test used to identify homogenous pixels based on the amplitude of co-registered and calibrated stack of SAR images. KS is a nonparametric test, i.e., the test does not assume that the variables belong to a defined distribution function. The most important parameter is the maximum absolute difference between two cumulative distribution functions. The distance between the distributions assess if the two points are statistically drawn from the same distribution. Specifically, DS are identified according to the following steps:

1. Selection and analysis of each single pixel of the image.

2. Creation of a window centered around the pixel.

3. Comparison of adjacent pixels with the KS test.

4. Further processing and analysis of statistically homogeneous pixels, while pixels with different distribution functions are discarded.

5. The DS identified within statistically homogeneous areas are processed using the traditional PSInSAR algorithm for the estimation of the deformation maps and the construction of displacement time series of each measurement point.

In accordance with Fig. 3, three main zones of ground deformation (A, B and C) are detected. Considering both the slope aspect and acquisition geometry, the registered displacements are consistent with active instability phenomena involving the Montescaglioso municipality, just outside of the town borders. Measurements very rarely show average velocities along the satellite line-of-sight (LOS) $>10 \mathrm{~mm} /$ year, with values that more often are between 1.5 and $5 \mathrm{~mm} /$ year. Even within the December 3, 2013, landslide perimeter (red line in Fig. 3), velocities were usually of few $\mathrm{mm}$ /year or sometimes basically stable (sector A). The uppermost sector where the city centre is located is clearly unaffected by significant movements.

In such situations, where the complexity in the local stratigraphy and geology make data interpretation more tentative, it can be difficult to generate a correct landslide susceptibility map and even more to achieve an accurate characterization and delimitation of the active phenomena. In the following sections, we perform a back-analysis of the interferometric data in order to get a more precise landslide map, displaying the areas affected by instability and classified after their hazard. Daily and cumulated rainfalls from July 2013 onward were also taken into consideration during the analysis. Rainfall data were collected at the Matera pluviometer.

\section{Analysis methodology}

Each of the 18,142 measuring points in the available CSK dataset has its own time series of cumulative displacement. The aim of the analysis herein is to describe the deformation behavior of each target by means of a distinctive threshold level; if at some point the latter is surpassed, an "anomaly" is identified. In other words, if a radar target shows a movement higher than the previously established threshold, it is inferred that the latest measured displacement of this particular point was not compliant with its previous deformation trend. It is of no significance to look at the occurrence of a single anomaly (a number of factors can theoretically degrade the accuracy of a single SAR displacement measurement), but attention should be rather put on the analysis of their temporal and spatial distribution. The few measurements made prior to October 2012 were discarded from the analysis methodology because of their poor frequency and distribution (Fig. 4).

Incremental displacements, calculated as the difference between subsequent measurements of cumulative displacements, were determined for each of the 18,142 radar targets, giving rise to an equal number of time series of incremental displacements:

$f(d)=d_{i}-d_{i-1}$

where $f(d)$ is the time series of incremental displacement for a single radar reflector and $d_{i}$ is the cumulative displacement measured at time $i$. As the time interval between adjacent acquisitions since October 2012 onward was not always constant (either 16 or 32 days, Fig. 4), incremental displacements were always normalized over 16 days, as follows:

$f^{\prime}(d)=16\left(d_{i}-d_{i-1}\right) /\left(t_{i}-t_{i-1}\right)$

where $t_{i}$ is the time measured in days. Normality tests were performed on a sample of these series of incremental displacements and showed that their distributions could be assumed to be consistent with a Gaussian distribution. Then, considering the normalized incremental displacements in absolute value $\left(\left|f^{\prime}(d)\right|\right)$, mean $(\mu)$ and standard deviation $(\sigma)$ characterizing the series at each point in time $\left(t_{i}\right)$ were sequentially found:

$S \mu=\ldots, \mu_{i-2}, \mu_{i-1}, \mu_{i}$,
$S \sigma=\ldots, \sigma_{i-2}, \sigma_{i-1}, \sigma_{i}$, 
At the end of this short procedure, all the 18,142 radar targets in the dataset are characterized by:

1. Series of normalized incremental displacements $\left(f^{\prime}(d)\right)$.

2. Series of normalized incremental displacements in absolute value $\left(\left|f^{\prime}(d)\right|\right)$.

3. Series of $\mu(S \mu)$.

4. Series of $\sigma(S \sigma)$.

Each absolute value of normalized incremental displacement in each of the 18,142 time series was compared to the sum between $\mu$ and $\sigma$ of the absolute incremental displacements relative to the preceding period. This means that, regarding for example the July 11 acquisition, mean and standard deviation of the series were estimated by taking into account only the measurements prior to that date (Table 1). The procedure was in fact applied beginning from the first acquisition of July 2013 and repeated for each successive CSK acquisition, in order to have an appropriate number of measurements for a representative calculation of the parameters $\mu$ and $\sigma$. Table 1 exemplifies the procedure: For radar target A013Y between 25 June and July 11, 2013, the measured incremental displacement $(0.18 \mathrm{~mm})$ is lower than the calculated $\mu+\sigma$ of the previous incremental displacements $(1.63 \mathrm{~mm})$; therefore, the point did not experience anomalous deformation during said time interval. If $\mu+\sigma$ had been $<0.18 \mathrm{~mm}$ or the displacement between the two CSK acquisitions $>1.63 \mathrm{~mm}$, an anomaly would have been registered. The same steps were applied to every radar reflector at every following measurement.

The final result is a temporal sequence of images of the Montescaglioso municipal area covered by the same 18,142 radar targets, which now though are not classified according to their average velocity but rather depending on the possible occurrence of an anomaly.

\section{Rainfall data}

2013 daily and cumulated precipitations were measured by the Matera pluviometer, $\approx 13 \mathrm{~km} \mathrm{SE}$ of the study area. With the exception of the winter season, in the study area rainfalls are usually not spread out evenly over time, but are instead concentrated on short and isolated periods of a few days or weeks which correspond to the passage of lowpressure systems or thunderstorms. For this reason such events give place to evident "spikes" in the plot of daily rainfalls (Fig. 5). Starting from the month of July four main rainfall events, or "spikes," can be distinguished in Fig. 5 in correspondence of the following time frames:

1. First half of July.

2. Mid-August (small and isolated).

3. Early October.

4. December 1-2, preceded by approximately half a month of constant (but not high-intensity) rainfall.

In particular, the December 2013 event was of exceptional intensity (with a peak of $125 \mathrm{~mm}$ on 1 December). Radar targets within the landslide area appear to be characterized by trends of cumulative displacements that mostly increase in accordance with the aforementioned rainfalls in July, October and December (Fig. 5). The latter are also the most intense precipitation events occurred during the year. The analysis of the distribution of the anomalies was therefore focused on the CSK images which were acquired in correspondence or immediately after these periods.

\section{Detection of anomalous ground deformation}

As the number of radar targets detected on the area by the SqueeSAR algorithm is extremely high, it is not convenient to conduct only a visual analysis of the maps of point anomalies generated as explained in Sect. 3.2. Eventual clusters of point anomalies could remain unnoticed. Data were re-sampled by means of a $150 \mathrm{~m}$ square mesh grid. This size was chosen to obtain a good compromise between data resolution and number of points contained in each square. Within each grid element, the total number of points and the number of "anomalous" points were counted; this procedure was repeated for every available image. Finally, the percentage of the anomalous points on the total of each square was obtained at every point in time. The
Table 1 Example showing the procedure performed for each radar target and for each CSK acquisition from July 2013 onward in order to produce characteristic and updateable thresholds of anomalous displacement

\begin{tabular}{ll}
\hline Radar target code & A013Y (mm) \\
\hline Cumulative displacement on July 11, 2015 & 6.75 \\
Cumulative displacement on June 25, 2013 & 6.57 \\
Incremental displacement from 25 June to July 11, 2013 & 0.18 \\
$\mu$ of previous incremental displacements (from October 28, 2012, to June 25, 2013) & 0.93 \\
$\sigma$ of previous incremental displacements (from 28 October 2012 to June 25, 2013) & 0.7 \\
$\mu+\sigma$ of previous incremental displacements (from October 28, 2012, to June 25, 2013) & 1.63 \\
Anomalous ground deformation between 25 June and July 11, 2013 & No
\end{tabular}




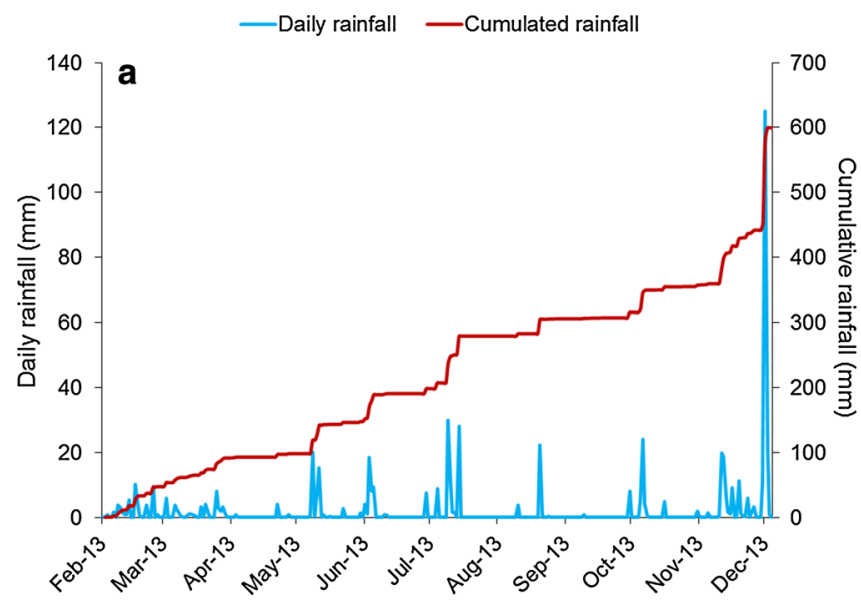

Fig. 5 a Daily and cumulated rainfalls, as registered at the Matera pluviometer from 1 February to December 2, 2013. b Daily rainfalls compared to the time series of cumulative displacement of radar

grid elements were thus distinguished according to the following classification scheme:

1. Percentage of "anomalous" points $<20 \% \rightarrow$ Class n. 1

2. Percentage of "anomalous" points $\geq 20 \%$ and $<30 \% \rightarrow$ Class n. 2

3. Percentage of "anomalous" points $\geq 30 \% \rightarrow$ Class n. 3

Grid elements containing less than six points were discarded in order to prevent a single point anomaly from generating a Class 2 or Class 3 area. The final result is a temporal sequence of maps of the Montescaglioso area, where each map refers to one of the dates when the satellite performed a SAR acquisition. It follows that this approach permits to get a sort of ever-updating monitoring map of anomalous ground deformation. Therefore, these can be considered as a sort of landslide susceptibility maps, meaning that large and/or high-risk gravity movements are most probably located where Class 2 and Class 3 grid elements are clustered.

Finally, the results were compared to information from two independently developed landslide maps of the Montescaglioso area, in order to verify the possible consistency between the detected clusters of anomalies and the actual presence of slope instabilities.

\section{Results}

\section{Analysis of the anomalies density}

To properly interpret data, it is again necessary not to focus on the single grid element, but to identify clusters and to verify their eventual repeated appearance over time. The information from the susceptibility maps was compared with the rainfalls data shown in Fig. 5. The results

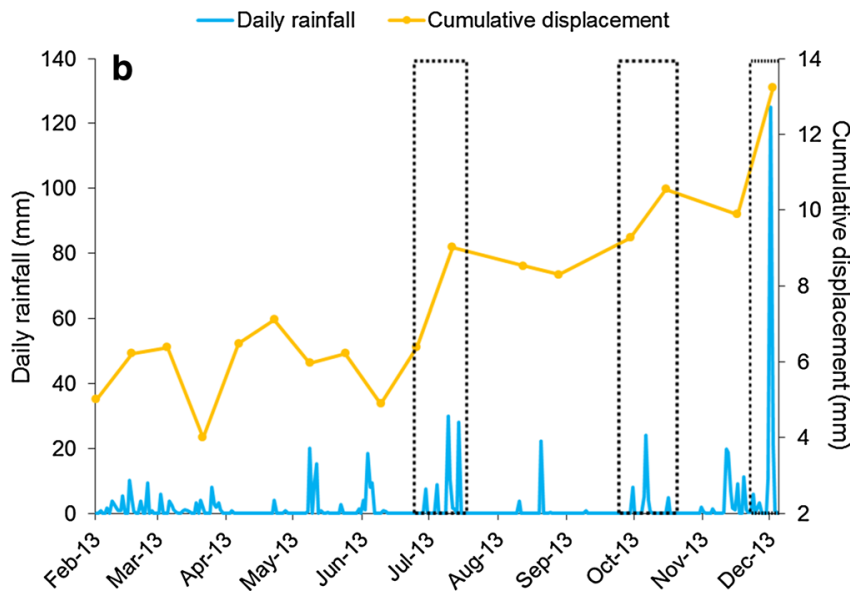

target A04EU, exemplifying the deformation in the landslide main scarp area before the December 3, 2013, event

indicated the presence of a relation between rainfall intensity and the appearance of anomalous ground deformation (Figs. 6 and 7): in images taken during dry months (i.e., August and September), the grid over the Montescaglioso municipality was found to be completely or mostly green (i.e., Class 1). Few anomalies were detected as well after isolated and/or low-intensity precipitations (Figs. 6b and 7), whereas these are significantly higher in correspondence of periods characterized by frequent and/or intense rainfalls (i.e., July and from October to December). In Fig. 7, the number of Class 2 and Class 3 grid elements for each CSK acquisition are displayed in relation to the amount of rainfall cumulated for the previous 4 weeks. In Fig. 6, the susceptibility maps obtained after the four main rainfall events pointed in Sect. 3.3 are presented. Four main areas marked as susceptible to instability are found to appear somewhat consistently in these instances. Relatively to the town, these are located NW, SW (in proximity of the December 3 landslide perimeter and main scarp area), $\mathrm{S}$ and NE. The first two seem to show both the bigger extent and intensity in terms of anomalous ground deformation. Instead, the terrain over which the dwelling is built basically remains unaffected by the occurrence of anomalies, in accordance with what would be expected from geological data (top of the hill characterized by consolidated conglomerates) and by radar targets average velocities (Fig. 3). Such results, though giving a first heads-up on where the critical sectors might be situated along the hill slopes, are certainly not sufficient per se and therefore were compared to ancillary data. Moreover, the delimitation of the critical sectors is for obvious reasons not strictly precise, but instead gives a rather general indication of where the instabilities might be situated. In the following section, two independently developed landslide maps have been reported for comparison. 


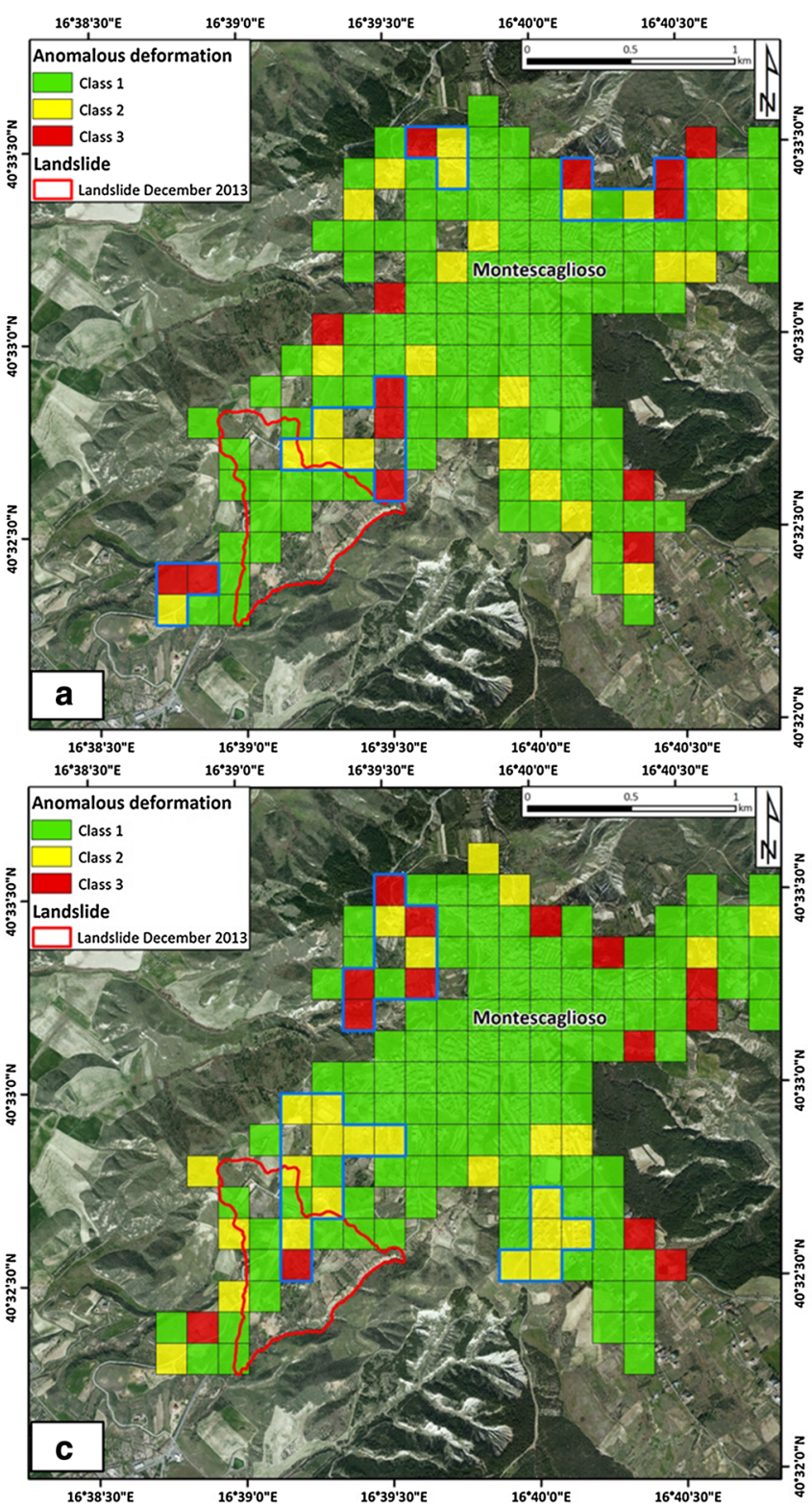

Fig. 6 Maps of anomalous deformation generated by the analysis of SqueeSAR interferometric data. Each map is referred to a date of CSK acquisition of the Montescaglioso municipal area. Shown here

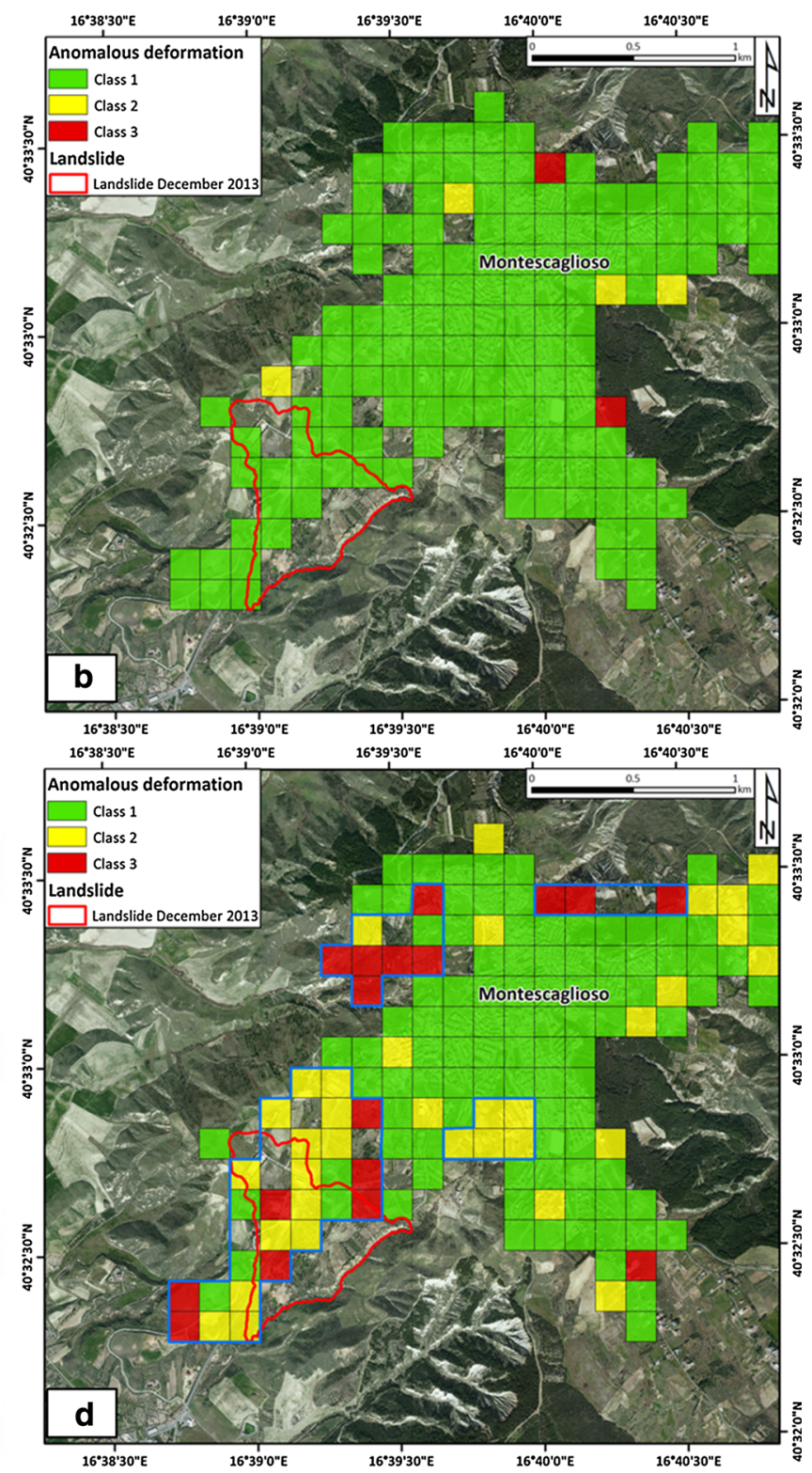

are the July 11 (a), August 28 (b), October 15 (c) and December (d) 2, 2013, acquisitions. Blue lines contain the recurrent clustering of anomalous grid elements

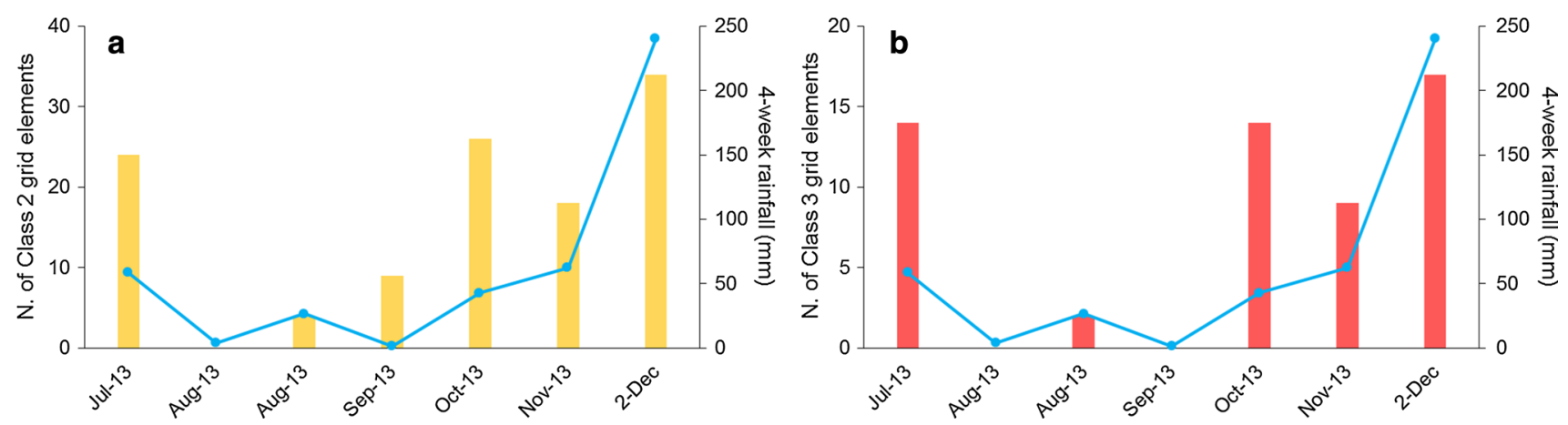

Fig. 7 Number of Class 2 (a) and Class 3 (b) grid elements for each SAR acquisition from 11 July onward in relation to the amount of rainfall cumulated over the previous 4 weeks 


\section{Comparison with ancillary landslide maps}

Figure 6d shows the largest occurrence of anomalous ground deformation, leading to the detection of the maximum extent of the areas registered as potentially affected by instability during the period of this study. It is mentioned again that its data refer to December 2, 2013, one day after an exceptionally strong rainfall $(125 \mathrm{~mm})$ and one day before the triggering of the catastrophic landslide event SW of Montescaglioso. Figure 6d is also where the overlapping between the area of anomalous ground deformation and the December 3, 2013, landslide area is more pronounced. For this reason, in Fig. 8 two independently developed informative layers are reported and overlapped to the 2 December map of anomalous ground deformation. Specifically, these are:

- The PAI (Piano Assetto Idrogeologico, Plan of Hydrogeologic Setting) landslide hazard map for the 2013 year (1:10.000 scale), realized on behalf of the Basilicata regional authority. PAI maps are a national scale landslide inventory and are one of the main reference tools used by administrative bodies for the assessment and management of hydrogeological hazard in Italy. Based on the evaluation of their characteristics and of the elements at risk, landslides are classified on a scale from R1 (low risk) to R4 (very high risk).

- A geomorphologic photo-interpretation of the SW slope of the Montescaglioso town, performed by the Department of Earth Sciences of the University of
Firenze through the analysis of several aerial shots captured at different times in the last 50 years.

It can be noticed that in the PAI cartography the slope sector hit by the landslide on December 3 was not marked as at risk. In fact, only a small portion was deemed as a possible discharge area of an ancient gravity movement identified further upslope in proximity of the city center. Conversely, approximate overlapping between areas at risk in the PAI map and areas showing anomalous deformation in the InSARderived map of December 2, 2013, are found SW, NE and NW of the village. The latter case is of particular interest: The points velocity map in Fig. 3 mainly shows stable radar targets in that region, while the results of the analysis in Fig. $6 \mathrm{c}, \mathrm{d}$ indicate therein the presence of intense anomalous ground deformation (class 3 ). This is also confirmed by the PAI cartography (active landslide classified with a R4 warning level). This suggests that velocity values alone can sometimes be misleading. In fact two different radar targets, even if affected by the same amount of cumulative displacement over the same time interval (thus having the same average velocity), can achieve that cumulative movement through different paths, i.e., undergoing linear deformation or through intermittent "pulses" of accelerations (even of small intensity). Ultimately, evaluating this aspect can change the interpretation of the studied landslide and of the related hazard. On another note, other landslides marked in the PAI map are situated over vegetated areas; hence any analysis on those areas is prevented by the absence of SAR targets (Ferretti et al. 2006).

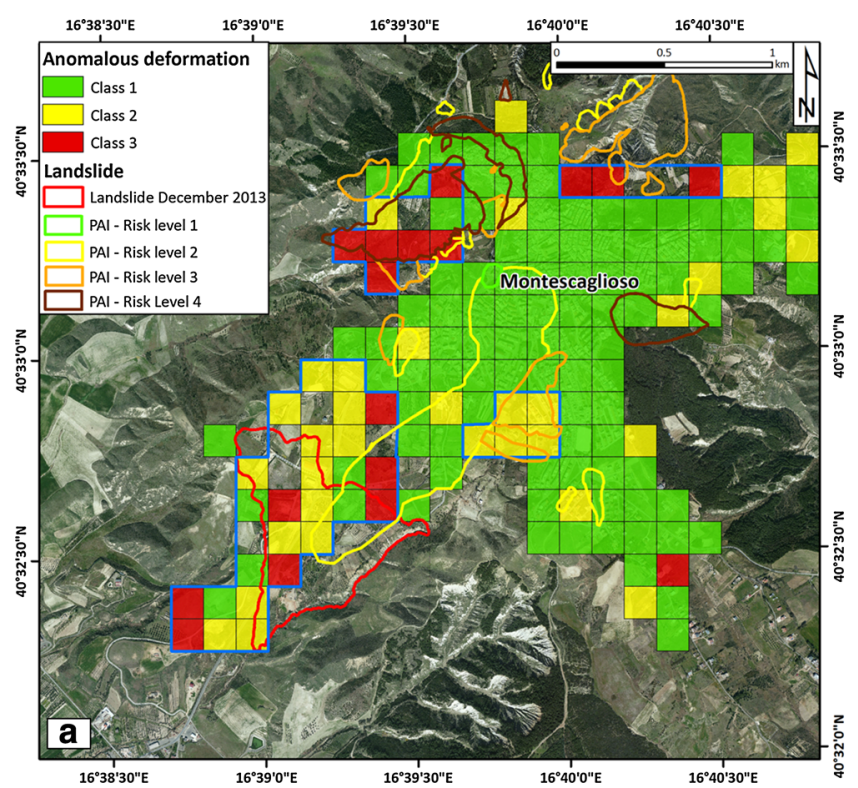

Fig. 8 a 2013 PAI landslide map for the Montescaglioso municipality and $\mathbf{b}$ geomorphologic photo-interpretation of the same area, both overlapped to the 2 December InSAR-derived map of anomalous

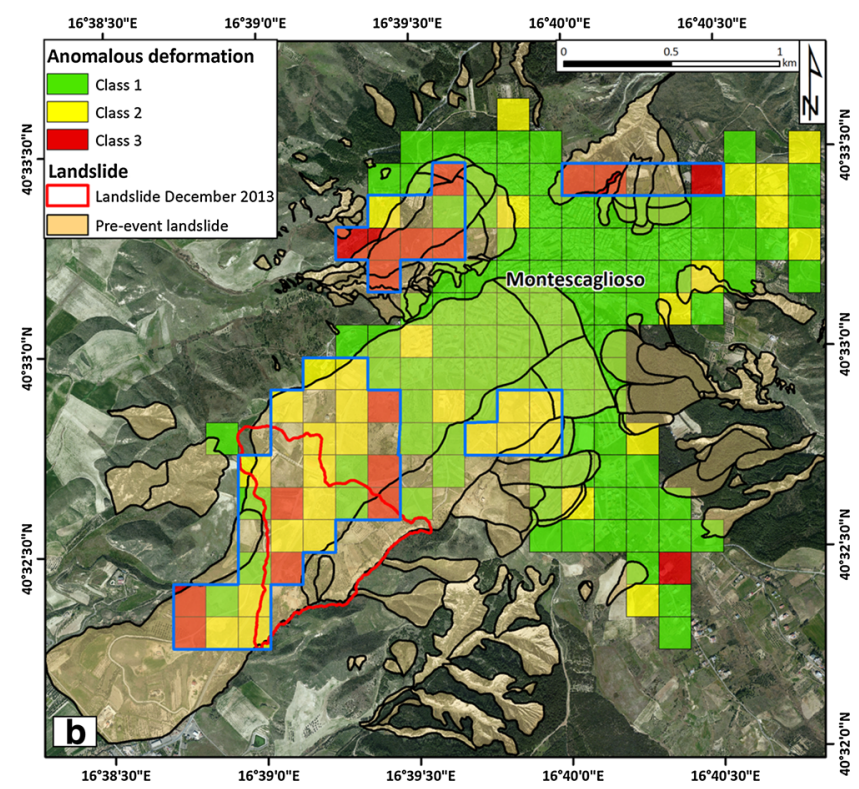

ground deformation. The red line encircles the limits of the December 3, 2013, landslide 
The geomorphologic photo-interpretation in Fig. 8b revealed the presence of landslides of different size, shape and age. Phenomena of slope instability are identified together with badlands, flows and forms of superficial erosion, underlining once again the tormented geomorphologic setting of the region. In particular, it is highlighted an extremely large movement involving the entire SW slope of the relief. Its geometry and internal structure are thought to be extremely complex, and the landslide can probably be subdivided into sectors of minor extent, which may be more prone to fast remobilization. It is inferred that this is what in fact occurred on December 3, 2013. In this case, results from an ancillary landslide informative stratum (Fig. 8b) and the InSAR-derived landslide susceptibility maps proposed here (Fig. 6) are in agreement with regard to the SW slope of Montescaglioso. The area of high susceptibility identified on that sector (especially in Fig. 6d) is entirely included within the limits of the large complex slide in Fig. 8b, which was detected through an independent and completely different analysis process.

\section{Discussion and conclusions}

On December 3, 2013, following a period of extremely intense rainfalls, the slope SW of the town of Montescaglioso (Matera, Southern Italy) was affected by a large complex landslide. Although no human losses were registered, the landslide caused the total collapse of a supermarket, of the principal route connecting the town with the regional road network and of several private dwellings (Fig. 1). The area is certainly not new to phenomena of gravitational instability, as expected from the geologic setting and the characteristics of the terrains in the upper part of the stratigraphic sequence. Indeed, plenty of geomorphologic features prove the fragility of the reliefs in this particular sector of the Apennines. Following the emergency, a set of 30 CSK interferometric images of the Montescaglioso area was acquired to perform a backanalysis of the displacements which preceded the event. This allowed also to assess all the active landslides in the surroundings of the town.

Field surveys, though always playing the main role in landslide hazard investigations, sometimes present technical and/or logistic impediments, giving raise to incomplete or outdated informative strata. Moreover, human error can potentially affect the perception of the active landslides, especially in areas characterized by high geological and geomorphologic complexity. This was evidently verified in the Montescaglioso case study, where the official landslide risk map did not indicate any hazardous phenomenon affecting the area actually hit by the landslide on December 3, 2013. From Fig. 8a, it can be hypothesized that the surveyors who realized the official PAI cartography identified (at least partially) the depletion zone of the large movement depicted also in Fig. 8b, but they did not detect its complex geometry and equally importantly they did not correctly evaluate the risk associated with possible fast remobilization of some of its sectors.

According to some of the evidences displayed in this work (Fig. 3), it is believed as well that using average velocities of radar targets alone may not be suitable in some local-scale analyses or sufficient to fully identify the anomalous ground movements and accelerations occurring on a certain site. It is important to evaluate the deformation path that each radar target follows over time to achieve a certain average velocity. This aspect was verified in the area NW of the town, where targets displayed low average velocities in mm/year (Fig. 3), despite the fact that they are situated on an active, high-risk landslide (Fig. 8a, b).

A quick and simple back-analysis of the SAR images recently acquired over the Montescaglioso municipal area was therefore performed with the intent of establishing characteristic and updatable thresholds of warning for each radar target identified on the ground. Since absolute values of incremental displacement are typically distributed as a Gaussian curve and the thresholds are defined as the sum between mean $(\mu)$ and standard deviation $(\sigma)$, a value exceeding the threshold (that is an anomaly) has a probability of occurring of $32 \%$. This also means that every measuring point has its own threshold which also varies with time (since $\mu$ and $\sigma$ are continuously updated with new data). Consequently a relative threshold based on probability enables to compare anomalies between faster and slower parts of the landslide, as they are not arbitrary and express an actual trend change in the series of displacements.

As measurements are in the form of time series, the same calculations were performed in sequence at each SAR acquisition time. The developed procedure can in fact be easily replicated and its application is not restricted only to SAR satellite time series, although satellite and aerial remote sensing techniques, with their ability to cover vast areas with great amounts of measuring points, certainly are ideally suited for such large scale analyses. "Anomalous" deformation was attributed to sectors where targets recurrently exceeded their specific threshold levels, with thresholds being based on the sum between the average and the standard deviation of the previous incremental displacements. The accuracy of the results was validated by their consistency with the available geomorphologic and pluviometric data. Together with other two independently developed landslide inventory maps, the procedure helped define, in retrospect, more precise landslide susceptibility maps and identify the slope sectors potentially more prone to instability in the area surrounding the municipality of 
Montescaglioso. A dependence between rainfall and slope displacements was also verified. Remarkably the largest cluster of anomalous ground deformation was found on the SW slope of the town 1 day earlier than the actual landslide, roughly in the same area where the event took place.

On the topic of risk assessment and management, the application of this procedure can suggest where further and more accurate field surveys and in situ investigations must be directed. While this type of methodology might in all probability be less responsive in cases of landslides generally characterized by steady movements (e.g., soil creep, slow mudflows and earthflows), its use may rather be of particular advantage in the case of landslides with a behavior driven for the most part by rainfall intensity, like in the Montescaglioso case study. The dependence between water and slope movements surely recurs frequently in most of the Apennines and in many regions worldwide as well (Canuti et al. 1985; Guzzetti et al. 2002, 2007; Martelloni et al. 2012; Rosi et al. 2012; Segoni et al. 2014). On the other hand, a long time series is essential in order to determine representative mean and standard deviation of the incremental displacements. Significant holes in the dataset should be avoided as well. The method is not applicable when radar reflectors are characterized by distributions of the incremental displacements which significantly differs from normality or when the displacement rates are too high to be captured with satellite interferometry. Moreover, the selection of the appropriate grid size and of the classification system for the grid elements is processes that may be influenced by the site-specific characteristics of the dataset and of the risk scenario. The user should always be aware that some simplifications are involved with the method. The latter may therefore be used to support the definition of landslide susceptibility maps and not as a stand-alone informative stratum.

The SqueeSAR technique permits to extract measuring targets from a great variety of objects on the ground (Ferretti et al. 2011); it is therefore necessary that SqueeSAR data are not solely analyzed based on average velocity values, but that also the characteristics of the elements constituting the measuring points are considered. Targets corresponding to man-made structures, due to, for example, structural deformations, may show different styles of deformation with respect to points placed on natural terrain. Establishing thresholds of anomalous movements for each radar target is therefore a more convenient approach, where again with "anomaly" it is meant a displacement which is not compliant with the previous trend of the deformation. On the topic of thresholds, other more robust procedures may be proposed for their definition. However, considering a scenario of risk emergency, it is recommended that this process remains as quick and simple as possible in order to reduce the possibility of human errors (Lacasse et al. 2008; Intrieri et al. 2012, 2013).

Given the short revisiting time of modern satellites (ASI 2007; Covello et al. 2010), the update rate of the InSARderived susceptibility maps could potentially be significantly higher than that of maps solely based on field surveys. A higher temporal resolution will also permit to improve the identification of the nonlinear components of ground deformation, i.e., accelerating and decelerating events (Herrera et al. 2011).

Finally, the method would surely benefit from further testing on other case studies where long satellite interferometric datasets are available, involving as well different types of landslides and/or different types of geologic and geomorphologic settings.

Open Access This article is distributed under the terms of the Creative Commons Attribution 4.0 International License (http://crea tivecommons.org/licenses/by/4.0/), which permits unrestricted use, distribution, and reproduction in any medium, provided you give appropriate credit to the original author(s) and the source, provide a link to the Creative Commons license, and indicate if changes were made.

\section{References}

Agenzia Spaziale Italiana (2007) COSMO-SkyMed Mission: system description \& user guide. http://www.e-geos.it/products/pdf/cskuser_guide.pdf. Accessed 10 Nov 2016

Canuti P, Focardi P, Garzonio CA (1985) Correlation between rainfall and landslides. Bull Int Ass Eng Geo 32(1):49-54

Ciampalini A, Raspini F, Lagomarsino D, Catani F, Casagli N (2016) Landslide susceptibility map refinement using PSInSAR data. Rem Sens Env 184:302-315

Cigna F, Del Ventisette C, Liguori V, Casagli N (2011) Advanced radar-interpretation of InSAR time series for mapping and characterization of geological processes. Nat Haz Earth Syst Sci 11:865-881

Covello F, Battazza F, Coletta A, Lopinto E, Fiorentino C, Pietranera L, Valentini G, Zoffoli S (2010) COSMO-SkyMed: an existing opportunity for observing the Earth. J Geodyn 49:171-180

Cruden DM, Varnes DJ (1996) Landslide types and processes. In: Turner AK, Schuster RL (eds) Landslides: investigation and mitigation. National Academy Press, Washington, pp 36-75

D'Ecclesiis G, Lorenzo P (2006) Frane relitte nei depositi della fossa bradanica: la frana di Madonna della Nuova (Montescaglioso, Basilicata). Giornale di Geologia Applicata 4:257-262 (In Italian)

Farina P, Casagli N, Ferretti A (2007) Radar-interpretation of InSAR measurements for landslide investigations in civil protection practices.In: First North American Landslide Conference, Vail, Colorado, June 3-8, 2007

Ferretti A, Cespa S, Novali F, Perissin D, Rocca F, Prati C (2006) PSInSAR: using satellite radar data to measure surface deformation remotely. In: 3rd IAG/12th Symposium, Baden, May 22-24, 2006

Ferretti A, Fumagalli A, Novali F, Prati C, Rocca F, Rucci A (2011) A new algorithm for processing interferometric data-stacks: squeeSAR. IEEE Trans Geosci Rem Sen 49(9):3460-3470 
Guzzetti F, Malamud BD, Turcotte DL, Reichenbach P (2002) Powerlaw correlations of landslide areas in central Italy. Earth Planet Sci Lett 195(3-4):169-183

Guzzetti F, Peruccacci S, Rossi M, Stark CP (2007) Rainfall thresholds for the initiation of landslides in central and southern Europe. Meteor Atm Phys 98(3):239-267

Herrera G, Notti D, Garcia-Davalillo JC, Mora O, Cooksley G, Sánchez M, Arnaud A, Crosetto M (2011) Analysis with C- and X-band satellite SAR data of the Portalet landslide area. Landslides 8:195-206

Intrieri E, Gigli G, Mugnai F, Fanti R, Casagli N (2012) Design and implementation of a landslide early warning system. Eng Geol 147-148:124-136

Intrieri E, Gigli G, Casagli N, Nadim F (2013) Brief communication: landslide early warning system: toolbox and general concepts. Nat Haz Earth Sys Sci 13:85-90

Lacasse S, Nadim F (2008) Landslide risk assessment and mitigation strategy. In: The First World Landslide Forum, United Nations University, Tokyo, Japan, 18-21 November 2008, pp 31-61

Lazzari M (2008) Il comportamento tettonico e sedimentario del bacino d'avanfossa Bradanica durante il Pleistocene inferiore. Mem Descr Carta Geol d'It 77:61-76 (In Italian)

Lazzari M, Pieri P (2002) Modello stratigrafico-deposizionale della successione regressiva infrapleistocenica della Fossa bradanica nell'area compresa tra Lavello, Genzano e Spinazzola. Mem Soc Geol It 57(1):231-237 (In Italian)

Lu P, Catani F, Tofani V, Casagli N (2014) Quantitative hazard and risk assessment for slow-moving landslides from Persistent Scatterer Interferometry. Landslides 11(4):685-696

Martelloni G, Segoni S, Fanti R, Catani F (2012) Rainfall thresholds for the forecasting of landslide occurrence at regional scale. Landslides 9(4):485-495

Metternicht G, Hurni L, Gogu R (2005) Remote sensing of landslides: an analysis of the potential contribution to geo-spatial systems for hazard assessment in mountain environments. Rem Sens Env 98:284-303
Oliveira SC, Zêzere JL, Catalão J, Nico G (2015) The contribution of PSInSAR interferometry to landslide hazard in weak rockdominated areas. Landslides 12(4):703-719

Piacentini D, Devoto S, Mantovani M, Pasuto A, Prampolini M, Soldati M (2015) Landslide susceptibility modeling assisted by Persistent Scatterers Interferometry (PSI): an example from the northwestern coast of Malta. Nat Haz 78(1):681-697

Raspini F, Moretti S, Casagli N (2013) Landslide mapping using SqueeSAR data: Giampilieri (Italy) case study. In: Margottini C, Canuti P, Sassa K (eds) Landslide Science and Practice, vol 1. Springer, Berlin, pp 147-154

Raspini F, Ciampalini A, Del Conte S, Lombardi L, Nocentini M, Gigli G, Ferretti A, Casagli N (2015) Exploitation of amplitude and phase of satellite SAR images for landslide mapping: the case of Montescaglioso (South Italy). Rem Sens 7:14576-14596

Righini G, Del Ventisette C, Costantini M, Malvarosa F, Minati F (2008) Space-born SAR analysis for landslides mapping in the framework of the PREVIEW project. In: Proceedings of the First World Landslide Forum, Tokyo, Japan, 18-21 November 2008, pp 505-506

Rosi A, Segoni S, Catani F, Casagli N (2012) Statistical and environmental analyses for the definition of a regional rainfall threshold system for landslide triggering in Tuscany (Italy). J Geog Sci 22(4):617-629

Segoni S, Rosi A, Rossi G, Catani F, Casagli N (2014) Analysing the relationship between rainfalls and landslides to define a mosaic of triggering thresholds for regional-scale warning systems. Nat Hazard Earth Syst Sci 14:2637-2648

Strozzi T, Farina P, Corsini A, Ambrosi C, Thüring M, Zilger J, Wiesmann A, Wegmüller U, Werner C (2005) Survey and monitoring of landslide displacements by means of L-band satellite SAR interferometry. Landslides 2(3):193-201

Tofani V, Raspini F, Catani F, Casagli N (2013) Persistent Scatterer Interferometry (PSI) technique for landslide characterization and monitoring. Rem Sens 5:105-1065 